\title{
Effect of Cooling on Vascular Smooth Muscle from the Thirteen-Lined Ground Squirrel ${ }^{1}$
}

\author{
CHRISTIAN T. HARKER AND R. CLINTON WEBB \\ Department of Physiology, The University of Michigan Medical School, Ann Arbor, Michigan 48109
}

\begin{abstract}
Peripheral vascular resistance in the ground squirrel (Spermophilus tridecemlineatus) increases when the animal enters hibernation. The goals of this study were (1) to determine if a change in vascular reactivity contributes to this hemodynamic response, and (2) to compare the effects of temperature on vascular responsiveness in a hibernator (ground squirrel) and a nonhibernating mammal (rat). Helically cut strips of aortae and femoral arteries were mounted in organ chambers $\left(37^{\circ} \mathrm{C}\right)$ and isometric contractions were recorded. The arteries were made to contract in response to exogenous norepinephrine $\left(5.9 \times 10^{-7} \mathrm{M}\right)$. Cooling the organ chamber $\left(11^{\circ} \mathrm{C}\right)$ potentiated contractions to norepinephrine $(5-15 \%$ increase) in ground squirrel femoral arteries but depressed those $(80-100 \%$ decrease) in ground squirrel aortae and rat aortae and femoral arteries. Contractions in response to depolarizing concentrations of potassium in ground squirrel femoral arteries were depressed by cooling $\left(11^{\circ} \mathrm{C}\right)$, suggesting that the augmented response to norepinephrine at low temperature is specific. Treatment with indomethacin, propanolol, and ouabain did not alter the potentiating effect of temperature on contractions to norepinephrine in ground squirrel femoral arteries. Apparently, the potentiation is not related to prostaglandins generated in the vascular wall, to blockade of $\beta$-adrenergic receptors, nor to inhibition of the electrogenic sodium pump. The observations are consistent with the hypothesis that a change in vascular responsiveness contributes to the regional control of blood flow in hibernation. This adaptive response is specific in that it does not occur in the aorta of the ground squirrel and the response is not present in the vasculature of the rat, a nonhibernating mammal. (1) 1987 Academic Press, Inc.
\end{abstract}

As an animal enters hibernation, peripheral vascular resistance increases $(1,2,5$, $6,15,17)$. While this increase is said to be generalized, it does not occur in all vascular beds, nor is it of equal magnitude in the beds where it does occur (12). Blood is preferentially shunted to the heart, brain, lungs, and brown fat at the expense of most visceral organs and the posterior portion of the animal. Lyman and O'Brien (7) suggested that although some of the changes observed in blood flow were attributable to a temperature-dependent increase in blood viscosity, an increase in vascular tone was also a contributing factor. Maclean (8) re-

Received May 23, 1986; accepted October 21, 1986.

1 These studies were supported by a grant from the National Institutes of Health (HL-27020). R.C.W. is a recipient of a Research Career Development Award from the National Institutes of Health (HL-00813). ported that several characteristics of hibernators' blood combined to make it unlikely that an increase in blood viscosity was a major contributor to the observed increase in vascular resistance. The extent of involvement of the nervous system and vasomotor tone in maintaining peripheral vascular resistance during hibernation is less clear.

The rise in vascular resistance seen in an animal entering hibernation is mirrored by the fall in the parameter upon arousal ( 2 , 5). At that time, flow to the heart, brain, lungs, and brown fat is maintained or increased, and that to the posterior section and other areas receiving low flow during deep hibernation is increased. Bullard and Funkhouser (2) have attributed the increased flow in the posterior portion of the animal to an effect of the warmed blood being delivered at a higher pressure and thus physically distending the vasculature. 
Conversely, Kirkebo (4) states, "There must be an important autoregulatory effect giving (rise to) higher local resistance in the cold" and a lower resistance at higher temperatures.

The mechanism underlying the control of regional blood flow in the hibernating and arousing animal has been the subject of speculation. While some authors have concluded that sympathetic tone plays a role in regulating regional blood flow during hibernation, that role remains undefined (7). It is possible that the blood vessels of hibernators are specially adapted, particularly those which distribute blood to peripheral tissues, to enable them to maintain vascular tone at low temperatures. In this report, we describe experiments designed to assess the direct effect of temperature on isolated adrenergically stimulated vascular smooth muscle (the aorta and the femoral artery) from a hibernator, the thirteen-lined ground squirrel, and a nonhibernator, the laboratory rat.

\section{MATERIALS AND METHODS}

Adult thirteen-lined ground squirrels (Spermophilus tridecemlineatus) were livetrapped in the vicinity of Ann Arbor, Michigan, during the summer months. Animals (80-200 g body wt) were housed at an ambient temperature of $22 \pm 1{ }^{\circ} \mathrm{C}$ and given sunflower seeds (supplemented with fresh fruit and vegetables) and water ad libitum until being used during the fall and winter months. Normothermic ground squirrels of either sex (core temperature ca. $37^{\circ} \mathrm{C}$ ) were decapitated and the aorta and the femoral arteries were removed. Vessels were stored $\left(1-2 \mathrm{hr}\right.$ at $\left.4^{\circ} \mathrm{C}\right)$ in physiologic salt solution (PSS) and cut into helical strips $(0.8 \times 8$ $\mathrm{mm}$ ) using a dissecting microscope. The helical strips were mounted in a $50-\mathrm{ml}$ tissue bath with one end held stationary and the other connected to a force transducer to measure isometric contractions which were recorded on a Grass polygraph. Resting tension was adjusted to an op- timum by examining contractile responses to norepinephrine $\left(5.9 \times 10^{-7} \mathrm{M}\right)$ and the strips were allowed to equilibrate for $60-90$ min in PSS (without drugs), maintained at $37^{\circ} \mathrm{C}$ and gassed with a mixture of $95 \% \mathrm{O}_{2}$ and $5 \% \mathrm{CO}_{2}$. The solution had a pH of 7.2 at $37^{\circ} \mathrm{C}$ and the following composition (in $\mathrm{m} M$ ): $\mathrm{NaCl}, 130 ; \mathrm{KCl}, 4.7 ; \mathrm{NaH}_{2} \mathrm{PO}_{4}$, 1.18; $\mathrm{MgSO}_{4}-7 \mathrm{H}_{2} \mathrm{O}, 1.17 ; \mathrm{CaCl}_{2}-2 \mathrm{H}_{2} \mathrm{O}$, 1.6, $\mathrm{NaHCO}_{3}, 14.9$; dextrose, 5.5; $\mathrm{CaNa}_{2}$ EDTA, 0.03 .

Following the equilibration period, norepinephrine was added to the $37^{\circ} \mathrm{C}$ bathing solution to yield a final concentration of 5.9 $\times 10^{-7} M$. This concentration of norepinephrine was chosen because it produced a contraction that was approximately $75 \%$ of the maximal response. Due to its position on the concentration/response curve, this allowed detection and quantification of both potentiation and relaxation responses. After $5 \mathrm{~min}$, when the norepinephrine-induced contraction had stabilized, the bath temperature was quickly lowered to $11^{\circ} \mathrm{C}$. When the contractile response reached a stable level at this new temperature, the bath was reheated to $37^{\circ} \mathrm{C}$. The entire cooling and rewarming process took approximately $25 \mathrm{~min}$. Control strips, contracted with the same concentration of norepinephrine, showed sustained, stable force generation over this entire period. During the experimental periods, bath temperatures were regulated over the range of 37 to $11^{\circ} \mathrm{C}$. The extent of this range represents the animals' core temperatures during the active and hibernating states, respectively. Changes in bath temperature were brought about by cooling or heating the water in the water jacket surrounding the tissue bath using a Haake heating and refrigerating unit (supplemented with ice to speed cooling). Drugs used were norepinephrine (Levophed bitartrate, WinthropBreon Laboratories), indomethacin (Sigma Chemical Co.), ouabain (Nutritional Biochemicals), and propranolol (Ayerst Laboratories). Dosages for antagonists were 
based on the ability of the drug to prevent a response to its responsive agonist (i.e., propanolol and isoproterenol) or on experimental observations for the literature (indomethacin, see Ref. 11).

For comparative purposes, the same experiments were performed using aortae and femoral arteries from male SpragueDawley albino rats (300-350 g body wt).

Results are presented as means \pm standard error of the means (SEM). In all experiments, $n=$ number of animals. Statistical evaluations were determined by Student's $t$ test for unpaired data. A $P$ value of less than 0.05 was taken to indicate statistical significance between groups.

\section{RESULTS}

Figure 1 demonstrates the effects of temperature on contractile responsiveness of vascular segments from ground squirrels and rats. The arterial segments were made to contract in response to $5.9 \times 10^{7} \mathrm{M}$ norepinephrine at $37^{\circ} \mathrm{C}$ and, after reaching a plateau, the organ chamber was rapidly cooled to $11^{\circ} \mathrm{C}$. Contractile responses to norepinephrine in ground squirrel femoral arteries were potentiated by the cooling procedure (Fig. 1, top tracing). By contrast, contractile responses in aortic strips from ground squirrels and in aortic strips and femoral arteries from rats were depressed by the cooling procedure. Rewarming the arterial segments to $37^{\circ} \mathrm{C}$ reversed these changes in contractile force (Fig. 1). The patterns of contractile responses in arteries from six ground squirrels and four rats are summarized in Fig. 2.

To determine whether the potentiation of contractile responses to norepinephrine in ground squirrel arteries was specific for the agonist, arterial segments of these vessels were made to contract to either $5.9 \times 10^{-7}$ $M$ norepinephrine or $25 \mathrm{mM} \mathrm{KCl}$ at $37^{\circ} \mathrm{C}$ (Fig. 3, top panel). After the contractile responses reached a plateau, the organ chamber was cooled to $11^{\circ} \mathrm{C}$. Contractile responses to norepinephrine were potentiated by the cooling procedure, whereas contractile responses to $\mathrm{KCl}$ were inhibited (Fig. 3, bottom panel). Rewarming the arterial segments to $37^{\circ} \mathrm{C}$ caused the contractile responses to return to the initial level of force development.

To investigate specific mechanisms that may contribute to the potentiation of contractile responses to norepinephrine in ground squirrel femoral arteries upon cooling, three experiments were performed (Fig. 4): (1) treatment with $4 \times 10^{-7} \mathrm{M}$ propranolol to block $\beta$-adrenergic receptors, (2) treatment with $3 \times 10^{-5} M$ indomethacin to inhibit prostaglandin synthesis, and (3) treatment with $3 \times 10^{-5} M$ ouabain to inhibit the electrogenic sodium pump. In each experiment, the arteries were subjected to two cycles of the cooling procedure; the first cycle served as the control and the second as the drug treatment. Data were analyzed as a percentage of the contractile response to $5.9 \times 10^{-7} \mathrm{M}$ norepinephrine at $37^{\circ} \mathrm{C}$. Propranolol (Fig. 4A) and indomethacin (Fig. 4B) did not alter contractile responsiveness to norepinephrine in ground squirrel femoral arteries at $37^{\circ} \mathrm{C}$, whereas ouabain (Fig. $4 \mathrm{C}$ ) caused a small potentiation at this temperature. At $11^{\circ} \mathrm{C}$, contractile responses to norepinephrine were potentiated before and after each drug treatment. However, the magnitude of the potentiation induced by cooling was not altered by propranolol, indomethacin, or ouabain.

\section{DISCUSSION}

This study provides evidence indicating that contractile responses to norepinephrine in femoral arteries from ground squirrels are potentiated at cold temperatures. By contrast, it was observed that cooling inhibited contractile responses to norepinephrine in aortae from ground squirrels and in aortae and femoral arteries of rats. The mechanism responsible for the potentiating effect of cold temperatures in 


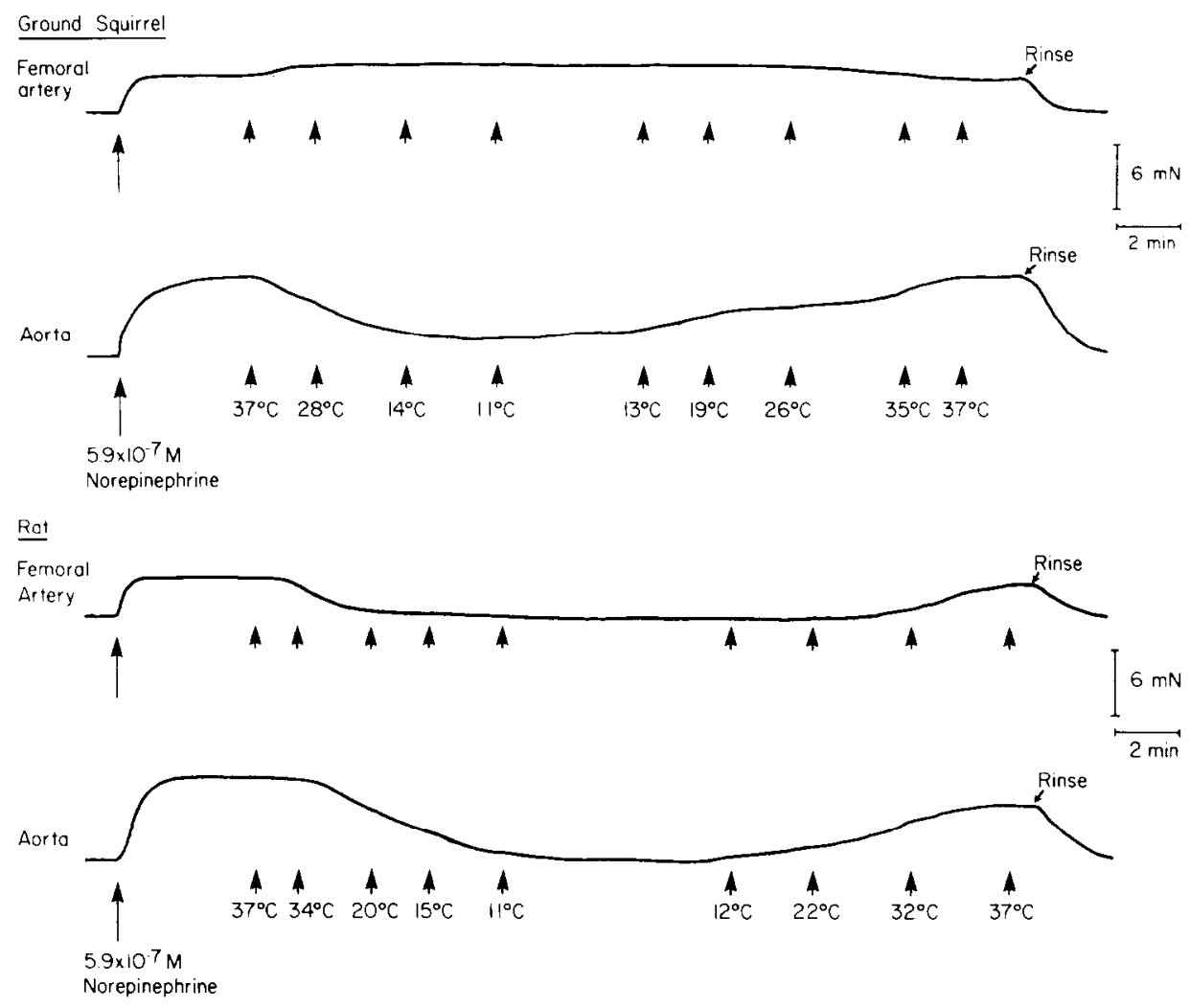

FIG. 1. Temperature and contractile responses to norepinephrine in femoral arteries and aortae from ground squirrels and rats. Contractile responses to norepinephrine in a femoral artery and aortic strip from a ground squirrel (top panel). Contractile responses to norepinephrine in a femoral artery and aorta from a rat that were depressed by cooling (bottom panel).

femoral arteries from ground squirrels is not related to the electrogenic sodium pump, prostaglandin metabolism, or blockade of $\beta$-adrenergic receptors. The potentiating effect was not observed in arteries contracted with elevated potassium, suggesting that the response to cooling is specifically related to a receptor-mediated event.

The results of this study differ from those of Wisnes et al. (16). They examined responsiveness to norepinephrine at various temperatures in the perfused hindlimb of the hedgehog (Erinaceous europaeus) and found that pressor responses of the catecholamine did not change at 32,22 , and $12^{\circ} \mathrm{C}$ compared with those at $37^{\circ} \mathrm{C}$. An explanation for these differences may be re- lated to specifics of the experimental protocol. Wisnes et al. first cooled the animals to a lower temperature before examining vascular responsiveness to norepinephrine. In the current study, the arterial strips were first contracted with norcpincphrine and then cooled, a procedure which may mimic that which occurs as an animal enters hibernation. Preliminary studies support this hypothesis - in four experiments, prior cooling to $11^{\circ} \mathrm{C}$ caused an inhibition of subsequent contractile responses to norepinephrine (data not shown). The precise reason for the different responses is not apparent but suggests that the order of events may be critical and may influence interpretation.

Different responses to cooling may be 

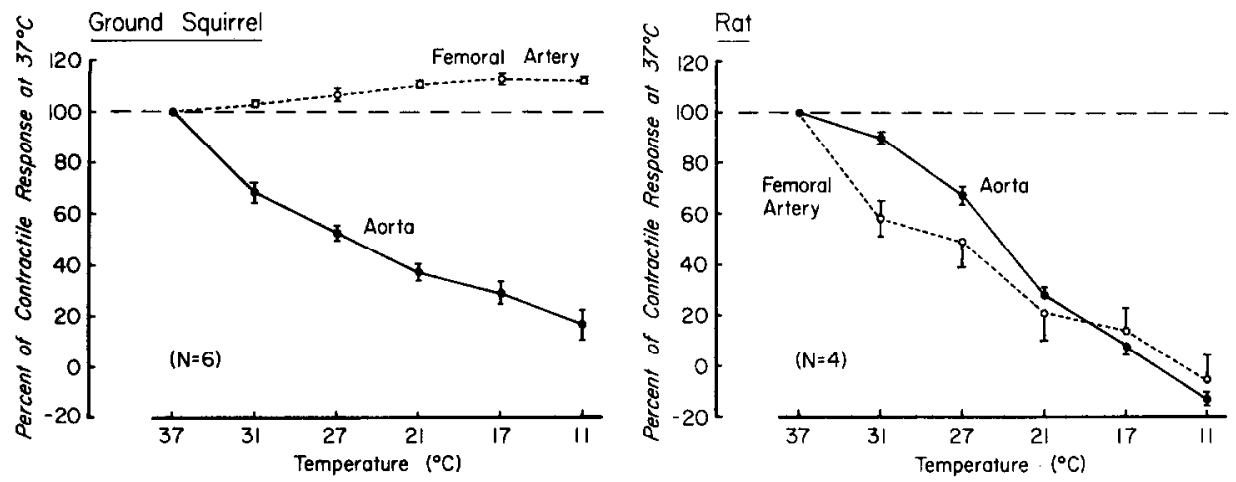

FIG. 2. Contractile responses to norepinephrine $\left(5.9 \times 10^{-7} M\right)$ during the cooling procedure: femoral arteries and aortae from ground squirrels (left) and rats (right). Values are the means \pm SEM for four rats and six ground squirrels.

related to the anatomical location of the blood vessel and to the species of animal. Miller et al. (10) observed that cooling augmented norepinephrine-induced contractile responses in isolated aortic strips from the woodchuck (a hibernator) but did not alter those in the femoral arteries from the same animals. Janssens and Vanhoutte (3) observed that cooling potentiated contractions to norepinephrine in dog saphenous vein but depressed those in the femoral vein of the same species. In the current experiments, cooling inhibited contractions to norepinephrine in aortic strips of ground squirrels but augmented those in femoral arteries from the same animals. The response appears to be species related since the augmentation did not occur in blood vessels of the rat.

Several experiments were conducted to determine the mechanism responsible for the cold-induced potentiation observed in the ground squirrel femoral artery. To mimic the contractile response of norepinephrine but to bypass the agonist-receptor interactions, a depolarizing solution of $\mathrm{KCl}(25 \mathrm{mM})$ was added to the tissue bath. Under these conditions, both aortic and femoral strips responded with relaxation to the cooling procedure. The fact that vessels contracted with $\mathrm{KCl}$-induced depolarization did not show the same re- sponse to cooling as they did when contracted with norepinephrine argues that the mechanism for the potentiation may be at the receptor level. Miller et al. (10) have also observed inhibitory responses to cooling after contraction induced by potassium in arteries from the woodchuck that show augmented responses to norepinephrine at low temperature.

Cold is known to inhibit sodium potassium pump activity in many systems ( 9 , 13). It is possible that the cold-induced potentiation of the norepinephrine contraction seen in the ground squirrel femoral artery strips was caused by pump inhibition and subsequent membrane depolarization. To evaluate this possibility, a maximally effective concentration of ouabain was added to the bath following norepinephrine stimulation at $37^{\circ} \mathrm{C}$. The inability of ouabain to duplicate the effect of cooling, coupled with the demonstration that cooling after ouabain treatment still resulted in a potentiation in the femoral artery strip, implies that inhibition of the electrogenic pump by low temperature is not responsible for the different responses seen in the two vessel types.

Ground squirrel femoral artery strips contract when stimulated with prostaglandin $F_{2 \alpha}$ (data not shown) and blood vessels have the capacity to synthesize 

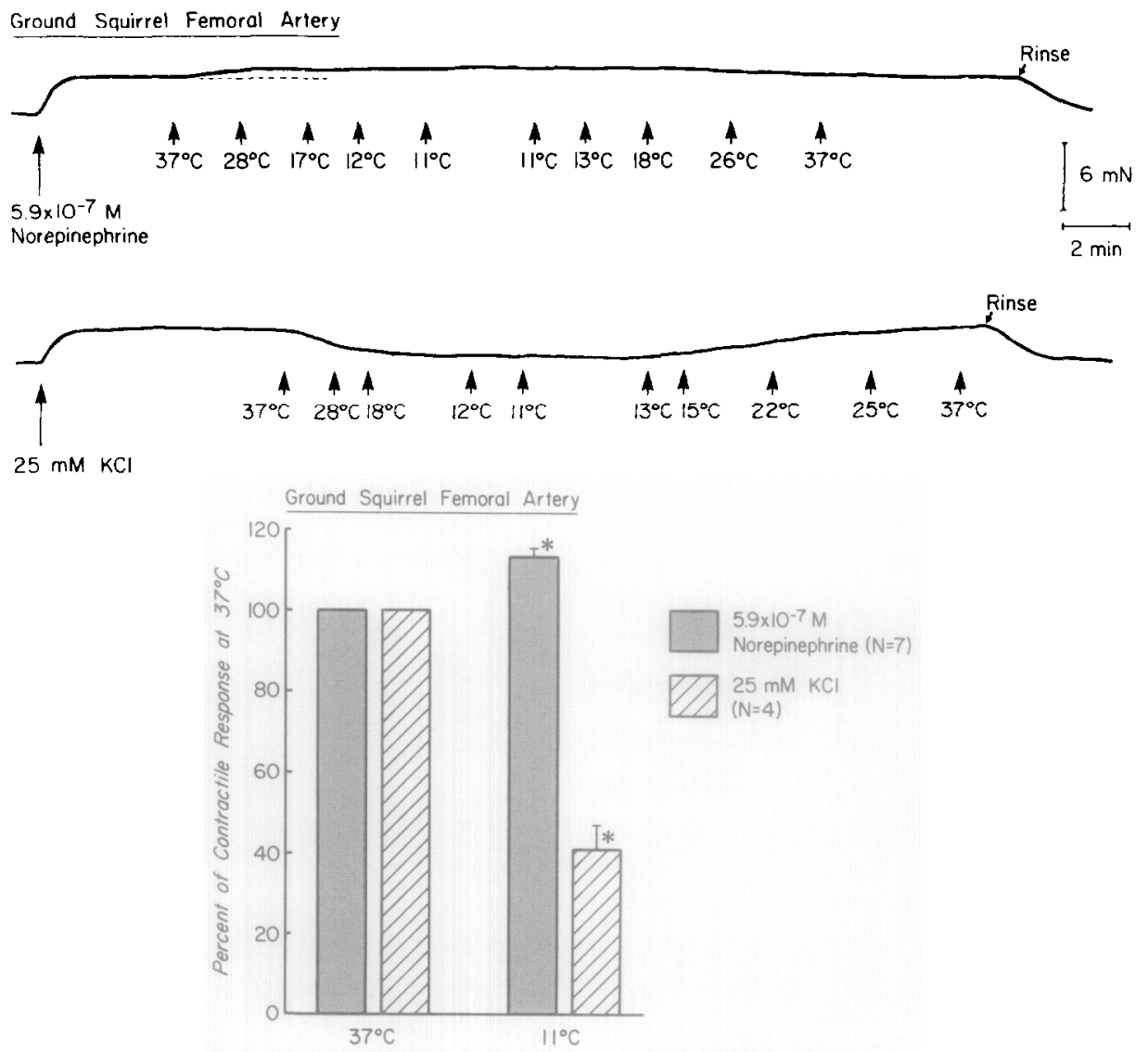

FIG. 3. Temperature and contractile responses to norepinephrine $\left(5.9 \times 10^{-7} M\right)$ and elevated potassium $(25 \mathrm{mM})$ in ground squirrel femoral arteries (top panel). The bottom panel summarizes experimental results for four to seven ground squirrels. Values are the means \pm SEM. Asterisks indicate statistical differences between 11 and $37^{\circ} \mathrm{C}(P<0.05)$.

prostaglandins (11). To determine whether this synthesis was necessary for the coldinduced potentiation to occur, ground squirrel femoral artery strips were incubated with the cyclooxygenase inhibitor, indomethacin, prior to stimulation with norepinephrine. The cold-induced potentiations were not significantly different from those observed in untreated vessels, implying that the phenomenon is not prostaglandin mediated.

Another possible explanation of the potentiation in the femoral strips would be a cold-induced decrease in $\beta$-adrenoceptormediated relaxation. To evaluate this possibility, ground squirrel femoral strips were incubated with the $\beta$-adrenoceptor antagonist, propranolol, prior to stimulation with norepinephrine. Vessels treated in this way and then cooled showed potentiation not significantly different from that in arteries not exposed to propranolol.

In summary, these data provide direct evidence of a local response that may increase the tone of a particular vessel (e.g., femoral artery) in a temperature-dependent manner. This effect may reflect a mechanism that contributes to increased peripheral vascular resistance when the animal enters hibernation. The effect is not due to the electrogenic sodium potassium pump bcing inhibited by cooling, nor is it prosta- 

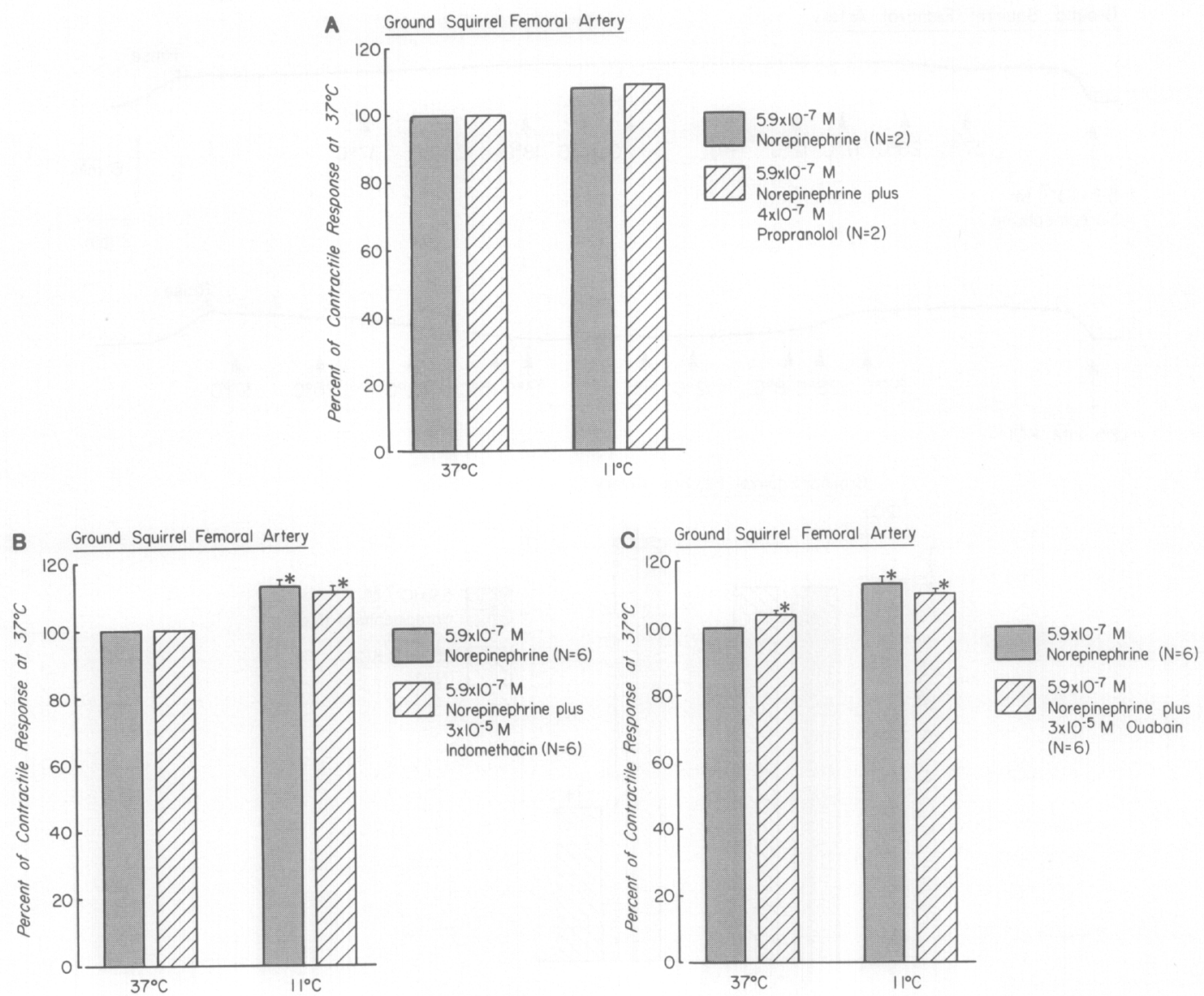

Fig. 4. Contractile responses to norepinephrine $\left(5.9 \times 10^{-7} M\right)$ in femoral arteries from ground squirrels and treatment with (A) propranolol $\left(4 \times 10^{-7} M\right)$, (B) indomethacin $\left(3 \times 10^{-5} M\right)$, and (c) ouabain $\left(3 \times 10^{-5} M\right)$. Values are the means \pm SEM, with number of animals in parentheses. Asterisks indicate statistical differences between treated values at $37^{\circ} \mathrm{C}$ and untreated values at $37^{\circ} \mathrm{C}$ or responses obtained at $11^{\circ} \mathrm{C}(P<0.05)$.

glandin mediated. It is not observed in vessel strips contracted with a depolarizing solution of $\mathrm{KCl}$, implying that the phenomenon may occur at the receptor level, and the potentiation is not mediated by blockade of $\beta$-adrenergic responsiveness. This response in the femoral artery of the ground squirrel resembles that in cutaneous veins of other mammals (14) and is not present in femoral arteries of the rat. Temperature-dependent changes in either agonist efficacy and/or receptor affinity are possible mechanisms for such an event (3, 14).

\section{REFERENCES}

1. Albert, T. F., and Panuska, J. A. Regional heterothermy and cardiovascular responses during induced hypothermia in nonhibernated and hibernated woodchucks, Marmota monax. Comp. Biochem. Physiol. A Comp. Physiol. 60, 1-6 (1978).

2. Bullard, R. W., and Funkhouser, G. E. Estimated regional blood flow by Rubidium-86 distribution during arousal from hibcrnation. Amer. $J$. Physiol. 203, 266-270 (1962).

3. Janssens, W. J., and Vanhoutte, P. M. Instantaneous changes of alpha-adrenoceptor affinity caused by moderate cooling in canine cutaneous veins. Amer. J. Physiol. 234, H330II337 (1978). 
4. Kirkebo, A. Temperature effects on the viscosity of blood and the aorta distension from a hibernator, Erinaceous europaeus. Acta Physiol. Scand. 73, 385-393 (1968).

5. Kirkebo, A. Cardiovascular investigations on hedgehogs during arousal from the hibernating state. Acta Physiol. Scand. 73, 394-406 (1968).

6. Lyman, C. P., and O'Brien, R. C. Circulatory changes in the thirteen-lined ground squirrel during hibernation. Bull. Mus. Comp. Zool. 124, 353-372 (1960).

7. Lyman, C. P., and O'Brien, R. C. Autonomic control of circulation during the hibernating cycle in ground squirrels. J. Physiol. (London) 168, 477-499 (1963).

8. Maclean, G. S. Blood viscosity of two mammalian hibernators: Spermophilus tridecimlineatus and Tamias striatus. Physiol. Zool. 54, 122-131 (1981).

9. Malvin, G. M., and Webb, R. C. A comparative study of potassium-induced relaxation in vascular smooth muscle of tiger salamanders and rats. Amer. J. Physiol. 247, R100-R125 (1984).

10. Miller, V. M., Miller, W. L., and South, F. E. Vascular smooth muscle responsiveness in a hibernator: Effects of season and temperature. Amer. J. Physiol. 250, R77-R82 (1986).

11. Needleman, P., and Isakson, P. C. Intrinsic prostaglandin biosynthesis in blood vessels. In
"Handbook of Physiology: The Cardiovascular System. Vascular Smooth Muscle" (D. F. Bohr, A. P. Somlyo, and H. V. Sparks, Jr., Eds.), Vol. I, pp. 613-633. Amer. Physiol. Soc., Bethesda, MD, 1980.

12. Popovic, V. Cardiac output in hibernating ground squirrels. Amer. J. Physiol. 207, 1345-1348 (1964).

13. Schwartz, A., Lindemayer, G. E., and Allen, J. C. Sodium-potassium adenosine triphosphatase. Pharmacological, physiological and biochemical aspects. Pharmacol. Rev. 27, 3-134 (1975).

14. Vanhoutte, P. M. Physical factors of regulation. In "Handbook of Physiology: The Cardiovascular System. Vascular Smooth Muscle" (D. F. Bohr, A. P. Somlyo, and H. V. Sparks, Jr., Eds.), Vol. II, pp. 443-474. Amer. Physiol. Soc., Bethesda, MD, 1980.

15. Wells, L. H. Circulatory patterns of hibernators. Amer. J. Physiol. 221, 1517-1520 (1971).

16. Wisnes, A. R., Stene-Larsen, G., and Eliassen, E. The effect of low temperature on the pressure response to noradrenaline in a hibernating (hedgehog) and nonhibernating mammal (rat). Crybiology 16, 78-82 (1979).

17. Zatzman, M. L. Renal and cardiovascular effects of hibernation and hypothermia. Cryobiology 21, 593-614 (1984). 